\title{
Phylogenetic position of the North American isolate of Pasteuria that parasitizes the soybean cyst nematode, Heterodera glycines, as inferred from 16S rDNA sequence analysis
}

\author{
N. Atibalentja, ${ }^{1}$ G. R. Noel ${ }^{1,2}$ and L. L. Domier ${ }^{1,2}$
}

Author for correspondence: G. R. Noel. e-mail: g-noel1@uiuc.edu

\footnotetext{
1 Department of Crop Sciences, University of Illinois at

Urbana-Champaign,

Urbana, IL 61801, USA

2 Crop Protection Research Unit, USDA ARS, Urbana, IL 61801, USA
}

\begin{abstract}
A 1341 bp sequence of the 165 rDNA of an undescribed species of Pasteuria that parasitizes the soybean cyst nematode, Heterodera glycines, was determined and then compared with a homologous sequence of Pasteuria ramosa, a parasite of cladoceran water fleas of the family Daphnidae. The two Pasteuria sequences, which diverged from each other by a dissimilarity index of $7 \%$, also were compared with the 165 rDNA sequences of 30 other bacterial species to determine the phylogenetic position of the genus Pasteuria among the Gram-positive eubacteria. Phylogenetic analyses using maximumlikelihood, maximum-parsimony and neighbour-joining methods showed that the Heterodera glycines-infecting Pasteuria and its sister species, P. ramosa, form a distinct line of descent within the Alicyclobacillus group of the Bacillaceae. These results are consistent with the view that the genus Pasteuria is a deeply rooted member of the Clostridium-Bacillus-Streptococcus branch of the Gram-positive eubacteria, neither related to the actinomycetes nor closely related to true endospore-forming bacteria.
\end{abstract}

Keywords: Heterodera glycines, Pasteuria sp., phylogeny, 16S rDNA sequence, soybean cyst nematode

\section{INTRODUCTION}

Pasteuria spp. are Gram-positive, mycelial and endospore-forming bacteria traditionally classified in the Actinomycetales (Sayre \& Starr, 1989). Four species of Pasteuria have been described, the first of which, Pasteuria ramosa (the type species), parasitizes cladoceran water fleas of the family Daphnidae (Ebert et al., 1996; Metchnikoff, 1888; Sayre et al., 1979, 1983). The other three species of Pasteuria are parasites of plantparasitic nematodes, against which they have shown great potential as biological control agents (Atibalentja et al., 1998; Brown et al., 1985; Chen et al., 1996, 1997; Duponnois \& Ba, 1998; Giblin-Davis, 1990; Gowen et al., 1998; Nishizawa, 1987; WeibelzahlFulton et al., 1996). The three species of nematodeinfecting Pasteuria are as follows: Pasteuria penetrans,

Abbreviations: ML, maximum likelihood; MP, maximum parsimony; NJ, neighbour-joining; RDP, Ribosomal Database Project.

The GenBank accession number for the 165 rDNA sequence of the North American isolate of Pasteuria reported in this paper is AF134868. which occurs on root-knot nematodes, i.e. Meloidogyne spp. (Sayre \& Starr, 1985; Starr \& Sayre, 1988); Pasteuria thornei, which affects root-lesion nematodes, i.e. Pratylenchus spp. (Starr \& Sayre, 1988); and Pasteuria nishizawae, which is parasitic on cyst nematodes of the genera Heterodera and Globodera (Sayre et al., 1991a, b). Members of the genus Pasteuria are widespread and have been reported from 323 nematode species belonging to 116 genera including plantparasitic, entomopathogenic, predatory and free-living nematodes (Chen \& Dickson, 1998; Ciancio et al., 1994; Sayre \& Starr, 1988; Sturhan, 1988).

Attempts to culture Pasteuria spp. in vitro have not been successful (Bishop \& Ellar, 1991; Williams et al., 1989). As a result, the taxonomy of the genus Pasteuria has been marked by a series of errors and confusion (Sayre \& Starr, 1989), as it relies mainly on morphological, developmental and pathological characteristics including the size and shape of the sporangium and endospore, ultrastructure, life cycle and host range (Davies et al., 1990; Giblin-Davis et al., 1990; Metchnikoff, 1888; Noel \& Stanger, 1994; Sayre \& Starr, 
1989; Sayre et al., 1991a, b; Starr \& Sayre, 1988; Sturhan et al., 1994). For the nematode-infecting Pasteuria, the taxonomic value of endospore morphometrics and host range was questioned when these characteristics were reported to reflect an evolutionary adaptation that occurred during host-nematode speciation (Ciancio, 1995). In addition, many of the Pasteuria isolates reported display a high degree of morphological similarity and others exhibit crossgeneric parasitism of nematodes (Chen \& Dickson, 1998). Clearly, morphological, developmental and pathological characteristics are not sufficient to accommodate the increasing number of Pasteuria isolates collected from soil and plant nematodes.

During the last few years, the analysis of $16 \mathrm{~S}$ rDNA and rRNA sequences has been used for the identification and classification of bacteria, including those that cannot be cultured (Relman et al., 1990, 1992; Woese, 1987). Recently, Ebert et al. (1996) questioned the position of the genus Pasteuria in the Actinomycetales based on the analysis of the 16S rDNA sequence of $P$. ramosa. Like other investigators (Sayre $\&$ Starr, 1985; Sayre \& Wergin, 1977), those authors observed some morphological similarities between $P$. ramosa and Thermoactinomyces spp. Unfortunately, they could not resolve the phylogenetic relationships between these organisms and Pasteuria spp., since there was no Thermoactinomyces sequence for comparison. Apart from that of $P$. ramosa, no $16 \mathrm{~S}$ rDNA sequence has been reported for Pasteuria spp., especially those infecting nematodes. Our objectives, therefore, were as follows: to determine the 16S rDNA sequence of a nematode-infecting Pasteuria, namely the North American isolate of Pasteuria that parasitizes the soybean cyst nematode, Heterodera glycines Ichinohe (Noel \& Stanger, 1994); to compare this sequence with that of $P$. ramosa (Ebert et al., 1996); and to resolve the phylogenetic position of the genus Pasteuria.

\section{METHODS}

Source of endospores. Pasteuria-infected $H$. glycines females and cysts were selected, on the basis of their opaque appearance, from the nematodes extracted from the rhizosphere of 3-month-old soybean plants grown in naturally infested soil in a greenhouse. The selected nematodes were transferred individually into $100 \mu \mathrm{l}$ tap water in $1.6 \mathrm{ml}$ microfuge tubes in which they were crushed with a tissue grinder; $10 \mu \mathrm{l}$ of the resulting suspension was examined microscopically for the presence of Pasteuria endospores. Positive fractions were pooled in a $1.6 \mathrm{ml}$ microfuge tube to form the stock suspension, which was then forced through a 5 - $\mu \mathrm{m}$-pore polycarbonate membrane filter (Poretics) to remove nematode debris. The endospore concentration of the suspension was determined with a Levy-Hausser counting chamber (Arthur H. Thomas) and the material was stored at $4{ }^{\circ} \mathrm{C}$ until used.

DNA extraction from Pasteuria endospores. DNA extraction was based on a modification of a procedure described by Ebert et al. (1996). Specifically, $500 \mu$ of a stock suspension containing $2 \times 10^{6}$ endospores $\mathrm{ml}^{-1}$ was transferred into a clean $1.6 \mathrm{ml}$ microfuge tube, which was then incubated for $10 \mathrm{~min}$ in a boiling water-bath. After cooling to room temperature $\left(24^{\circ} \mathrm{C}\right)$, the suspension was centrifuged for 15 min in an Eppendorf microcentrifuge at maximum speed (approx. $16000 \mathrm{~g}$ ) and the pellet was resuspended with $200 \mu 125 \mathrm{mg}$ lysozyme $\mathrm{ml}^{-1}$ solution in $10 \mathrm{mM}$ Tris $/ \mathrm{HCl}$ buffer, $\mathrm{pH} 8.0$. The mixture was incubated at $37^{\circ} \mathrm{C}$ for 30 min, at which point a $10 \%$ solution of SDS was added to a final concentration of $2 \%(\mathrm{v} / \mathrm{v})$; this was followed by an additional $30 \mathrm{~min}$ incubation at $37^{\circ} \mathrm{C}$. The endospores, which are resistant to heat, lysozyme and detergent treatments, were pelleted as before and washed twice by resuspending the pellet in $500 \mu 110 \mathrm{mM}$ Tris $/ \mathrm{HCl}$ buffer, $\mathrm{pH} 7 \cdot 0$; this was followed by $15 \mathrm{~min}$ centrifugation at high speed. The pellet from the last wash was resuspended in $500 \mu \mathrm{l}$ buffered solution ( $40 \mathrm{mM}$ Tris $/ \mathrm{HCl}, \mathrm{pH} 8 \cdot 0,10 \mathrm{mM}$ $\mathrm{NaCl}, 6 \mathrm{mM} \mathrm{MgCl}{ }_{2}$ and $10 \mathrm{mM} \mathrm{CaCl}$ ) containing $10 \mu \mathrm{g}$ (50 U ml ${ }^{-1}$ ) RQ1 RNase-free DNase $\mathrm{ml}^{-1}$ (Promega) to destroy any DNA released from contaminating microorganisms. The DNase reaction was conducted at $37^{\circ} \mathrm{C}$ for $30 \mathrm{~min}$, at which point the endospores were pelleted, washed twice and resuspended with $500 \mu \mathrm{l}$ of a solution containing $50 \mathrm{U}$ RNase One $\mathrm{ml}^{-1}$ (Promega) in RNase One buffer $(10 \mathrm{mM}$ Tris $/ \mathrm{HCl}, \mathrm{pH} 7 \cdot 5,5 \mathrm{mM}$ EDTA and $200 \mathrm{mM}$ sodium acetate). After $30 \mathrm{~min}$ incubation at $37^{\circ} \mathrm{C}$, proteinase $\mathrm{K}\left(50 \mu \mathrm{g} \mathrm{ml}^{-1}\right)$ and SDS $(0.5 \%, \mathrm{v} / \mathrm{v})$ were added and the mixture was incubated further at $55^{\circ} \mathrm{C}$ for $2 \mathrm{~h}$. The endospores were pelleted again, washed twice and resuspended in $500 \mu \mathrm{l}$ TE buffer $(10 \mathrm{mM}$ Tris $/ \mathrm{HCl}, 1 \mathrm{mM}$ EDTA, $\mathrm{pH} 8.0$ ) to produce the pre-lysis suspension.

To ascertain the absence of vegetative cells in the pre-lysis suspension, $15 \mu \mathrm{l}$ was examined microscopically and $100 \mu 1$ of a 1:10 dilution in sterile distilled water was spread on each of two Luria agar plates, which were incubated at $30^{\circ} \mathrm{C}$ for a week. As positive controls, two Luria agar plates were spread with equivalent amounts of the stock suspension that had not been subjected to either heat or enzyme treatments and incubated at $30^{\circ} \mathrm{C}$. Aliquots $(10 \mu \mathrm{l})$ of the pre-lysis suspension and the suspensions derived from representative colonies of the bacteria that grew on control plates were used in separate PCR reactions (see below), the products of which were sequenced to determine the identity of the DNAs in the suspensions. The remaining $455 \mu \mathrm{l}$ of the pre-lysis suspension was transferred into a fresh screw-capped $1.6 \mathrm{ml}$ microfuge tube containing $860 \mathrm{mg}$ acid-washed glass beads $(0 \cdot 150-0.212 \mathrm{~mm}$ in diameter) and $500 \mu \mathrm{l}$ Tris buffer (pH 8.0)-equilibrated phenol/chloroform/isoamyl alcohol (25:24:1, by vol.). Lysis of endospores was achieved with four $30 \mathrm{~s}$ pulses of bead-beating in a Mini-BeadBeater (BiosPec Products) operated at high speed in a cold room $\left(4{ }^{\circ} \mathrm{C}\right)$. The mixture was incubated on ice for 5 min between pulses of bead-beating. The lysate was centrifuged at maximum speed for $10 \mathrm{~min}$ and the aqueous phase was transferred into a fresh $1.6 \mathrm{ml}$ microfuge tube. The handling of the supernatant, thereafter, was according to standard procedures (Sambrook et al., 1989), which included chloroform: isoamyl alcohol $(24: 1, \mathrm{v} / \mathrm{v})$ extraction followed by DNA precipitation with $3 \mathrm{M}$ sodium acetate ( $\mathrm{pH} 5 \cdot 2$ ) and 2 vols ice-cold ethanol $(100 \%)$, then washing with $70 \%$ ethanol. The final pellet was resuspended with $50 \mu \mathrm{TE}$ buffer to make the post-lysis suspension, which was stored at $-20{ }^{\circ} \mathrm{C}$ until used.

DNA amplification and sequencing. The PCR primers (PrDNA-1 and PrDNA-2) were designed (Table 1) to amplify an approximately $1400 \mathrm{bp}$ region of the $16 \mathrm{~S}$ rDNA, 
Table 1. Primers used for PCR amplification and sequencing of the $16 \mathrm{~S}$ rDNA of the Heterodera glycines-infecting Pasteuria

\begin{tabular}{|lllc|}
\hline Name* $^{*}$ & Direction & \multicolumn{1}{c|}{$\mathbf{5}^{\prime} \rightarrow \mathbf{3}^{\prime}$ sequence } & Position of $\mathbf{5}^{\prime}$ nucleotide $\dagger$ \\
\hline 1 & Forward & GCGGCGTGCCTAATACA & 39 \\
2 & Reverse & ACGGGCGGTGTGTACAAG & $1388 \ddagger$ \\
3 & Forward & TACGGGAGGCAGCAGTA & 342 \\
4 & Reverse & TACTGCTGCCTCCCGTA & $342 \ddagger$ \\
5 & Forward & CCCTGGTAGTCCACGCG & 794 \\
6 & Reverse & CGCGTGGACTACCAGGG & $794 \ddagger$ \\
7 & Forward & TCGAGAGAGTGCTGTGCCC & 1011 \\
8 & Reverse & GGGCACAGCACTCTCTCGA & $1011 \ddagger$ \\
\hline
\end{tabular}

* Primers were designated by the generic name 'PrDNA- $X$ ', where $X$ is a number from 1 to 8 .

$\dagger$ Numbers refer to equivalent positions in the E. coli sequence (Brosius et al., 1978).

$\$$ The position of the $5^{\prime}$ nucleotide in the complementary sequence.

based on a comparison of published sequences from related Gram-positive bacteria including Bacillus subtilis, Bacillus caldolyticus, Bacillus validus, Thermoactinomyces vulgaris and Thermoactinomyces candidus (accession numbers of published sequences used in this study are listed at the end of this section). Additional primers were designed (Table 1) on the basis of preliminary sequencing results. The $50 \mu \mathrm{l} \mathrm{PCR}$ reactions $[10 \mu \mathrm{l}$ sample, $1 \times$ buffer $(20 \mathrm{mM}$ Tris $/ \mathrm{HCl}$, $\mathrm{pH} 8.4,50 \mathrm{mM} \mathrm{KCl}), 1.5 \mathrm{mM} \mathrm{MgCl}_{2}, 0.2 \mu \mathrm{M}$ each primer, $0.2 \mathrm{mM}$ each dNTP and 2.5 U Taq DNA Polymerase (Life Technologies)] were carried out in a GeneAmp PCR System 9700 (Perkin-Elmer, Applied Biosystems) using the following regimen: $94{ }^{\circ} \mathrm{C}$ for $10 \mathrm{~min}$; 30 cycles each of $1 \mathrm{~min}$ denaturation at $94{ }^{\circ} \mathrm{C}, 1 \mathrm{~min}$ primer annealing at $52^{\circ} \mathrm{C}$ and 2 min extension at $72^{\circ} \mathrm{C}$; final extension at $72^{\circ} \mathrm{C}$ for $5 \mathrm{~min}$; and incubation at $4^{\circ} \mathrm{C}$. The sizes of the amplicons were determined by loading $10 \mu \mathrm{l}$ on to a $1 \%$ agarose gel alongside a $1 \mathrm{kbp}$ DNA ladder (Life Technologies). Unincorporated primers, dNTPs and salts were removed from the amplicons using the QIAquick PCR purification kit (QIAgen). The concentration of the eluted DNA $(50 \mu \mathrm{l}$ DNA in $10 \mathrm{mM}$ Tris/HCl buffer, $\mathrm{pH} 8.5$ ) was estimated by comparing band intensities on agarose gel and by UVspectrophotometry.

The purified amplicons were sequenced using the ABI PRISM dye terminator cycle sequencing ready reaction kit with AmpliTaq DNA Polymerase, FS (Perkin-Elmer, Applied Biosystems), according to a protocol suggested by the manufacturers (except that the annealing temperatures were adjusted for each primer). The $20 \mu \mathrm{l}$ sequencing reactions (8 $\mu$ l terminator ready reaction mix, $75 \mathrm{ng}$ DNA template and $3.2 \mu \mathrm{M}$ primer) were conducted in the same GeneAmp PCR System 9700 used for PCR amplification. Sequencing products were purified prior to electrophoresis using CentriSep spin columns (Princeton Separations) according to the manufacturer's instructions. The sequencing products were dried in a vacuum microcentrifuge and forwarded to the Genetic Engineering Laboratory of the University of Illinois at Urbana-Champaign, where the pellets were resuspended and loaded into an automated ABI PRISM 377 sequencer according to the manufacturers' instructions.

Phylogenetic analysis. The various fragments of DNA sequence obtained from both strands were assembled with the multiple sequence editor SEQUENCHER (Gene Codes). The consensus sequence, hereafter referred to as $\mathrm{Hg}$ Pasteuria (Heterodera glycines-infecting Pasteuria), was submitted for sequence-similarity searches using the BLAST program (Altschul et al., 1990) and the SIMILARITY_RANK feature of the Ribosomal Database Project (RDP; Maidak et al., 1999). The SUGGEST_TREE option provided an approximate placement of $\mathrm{Hg}$ Pasteuria in the RDP maximum-likelihood tree. In addition to the sequences suggested by the above search methods, a set of sequences from a previous alignment involving $P$. ramosa (Ebert et al., 1996) and sequences from Anacystis nidulans and Escherichia coli (the latter two sequences were used as the outgroup) were retrieved from public databases and aligned with Hg Pasteuria, using the graphical multiple alignment software CLUSTALX $1.64 \mathrm{~b}$ (Thompson et al., 1997). The multiple alignment was edited manually to remove regions with long stretches of leading or trailing gaps. A measure of signal content was obtained using Relative Apparent Synapomorphy Analysis (RASA) with the program RASA 2.2 (Lyons-Weiler et al., 1996) before the data were subjected to phylogenetic analyses using maximum-likelihood (ML), maximum-parsimony (MP) and distance-based methods. The robustness of trees was assessed through bootstrap analysis (Felsenstein, 1985). The fastDNAml_loop script of fastDNAml 1.1.1a (Felsenstein, 1981; Olsen et al., 1994) was used for ML analysis with the following option settings: empirical base frequencies, a transition: transversion ratio of $2 \cdot 0$, global rearrangement, N_BEST 3 and MAXJUMBLE 10. The fastDNAml_boot script of the same software was also used to generate 100 bootstrap trees, which were fed into the CONSENSE program in the PHYLIP package (Felsenstein, 1993) to compute bootstrap proportions. MP analyses were based on informative sites only and were conducted with PAUP 3.1 (Swofford, 1993), using a heuristic search method with 100 random sequenceaddition replicates, steepest descent, MULPARS and TBR branch-swapping option settings. The same search method and options were used for bootstrap analysis of the MP trees based on 100 replicates with 10 random sequence addition replicates each. The PHYLO_WIN program (Galtier et al., 1996) was used to compute pair-wise evolutionary distances either from all sites or from parsimony sites only and to construct neighbour-joining (NJ) trees (Saitou \& Nei, 1987) based on LogDet-corrected distances (Lake, 1994; Lockhart et al., 1994). The NJ trees were evaluated through bootstrap resampling, with 1000 replicates each. 
Accession numbers. The accession numbers of published $16 \mathrm{~S}$ rDNA sequences used in this study are as follows: Actinomyces bovis, X81061; Alicyclobacillus acidocaldarius, X60742; Alicyclobacillus acidoterrestris, X60743; Alicyclobacillus cycloheptanicus, X51928; strain ALV, M79375, M79376, M80290; Anacystis nidulans, X03538, K01982, X01296; Aureobacterium liquefaciens, X77444; Bacillus caldolyticus, Z26924; Bacillus methanoliticus, X64465, S42879; Bacillus schlegelii, Z26934; Bacillus subtilis, D64126; Bacillus thermocatenulatus, Z26926; Bacillus thermocloacae, Z26939; Bacillus thermoruber, Z26921; Bacillus thuringiensis (strain IAM12077), D16281; Bacillus tusciae, Z26933; Bacillus validus, M77489; Clostridium difficile, X73450; Clostridium polysaccharolyticum, X71858; Escherichia coli, J01859, K02555, M24828, M24833-M24837, M24911, M24996; Flavobacterium heparinum, M11657, M61766, M81326; Heliobacterium chlorum, M11212; strain HTA1417, AB002649; Lactobacillus brevis (isolate L63), D37785; Megasphaera elsdenii, M26493; Oxalophagus oxalicus, Y14581; Paenibacillus apiarius, U49247; Paenibacillus validus (strain DSM3037), D78320; Pasteuria ramosa (Daphnia endosymbiontic bacterium), U34688; Planococcus citreus, X62172, S49897; strain Rt8B.4, L35151; Saccharococcus thermophilus, X70430; Thermoactinomyces candidus, M77490; Thermoactinomyces vulgaris, M77491; type 0803 unidentified filamentous bacterium, X86071.

\section{RESULTS}

\section{PCR amplification and sequencing of Pasteuria DNA}

Microscopic examinations revealed that the stock suspension of Pasteuria endospores contained many contaminating bacteria. In contrast, no contaminants were observed in the pre-lysis suspension. Likewise, no bacterial growth was observed on the Luria agar plates that were spread with the pre-lysis suspension and incubated for a week at $30^{\circ} \mathrm{C}$. Conversely, the control plates spread with the stock suspension contained several bacterial colonies after $48 \mathrm{~h}$ incubation under similar conditions. PCR reactions using the suspensions of representative bacterial colonies that grew on control plates as the template produced a single band, each of which was of the expected size (1400 bp). DNA sequences of those products matched the 16S rDNA of $F$. heparinum, A. liquefaciens or type 0803 of an unidentified filamentous bacterium following sequence-similarity searches with the BLAST program (Altschul et al., 1990). PCR reactions with either the pre- or the post-lysis suspension as the template also yielded a single product, each of which was of the expected size (1400 bp). DNA sequences of the products originating from the pre- or the post-lysis suspensions were identical. At least two fragments of DNA sequence were generated with each of the eight primers used to amplify and sequence DNA from either the pre- or the post-lysis suspension, for a total of 18 fragments derived from both DNA strands. When each of the 18 fragments was submitted for sequence-similarity searches using the BLAST program (Altschul et al., 1990), the 16S rDNA sequence of $P$. ramosa was always retrieved as the highest scoring segment with the query sequence. The 18 fragments were assembled with the multiple sequence editor SEQUENCHER (Gene Codes) to produce a $1341 \mathrm{bp}$ consensus sequence referred to as the $\mathrm{Hg}$ Pasteuria sequence. This sequence not only included the Pasteuria-specific oligonucleotide, 5'-CATTTCTTCTTCCCGATG-3' (Ebert et al., 1996), but also contained two oligonucleotides (5'-TACACCCCAGAGGATGCA-3' and 5'-GGGCACAGCACTCTCTCGA-3') that searches of the RDP database of $16 \mathrm{~S}$ rDNA probes revealed to be unique to the North American isolate of Pasteuria [the above sequences are from the minus strand and the positions of the $5^{\prime}$ residues in the complementary strand are 440, 69 and 1011, respectively, according to the $E$. coli numbering system (Brosius et al., 1978)].

\section{Phylogenetic relationships between $\mathrm{Hg}$ Pasteuria and other bacterial species}

The edited DNA sequence alignment comprised 1336 sites, including 531 informative sites under parsimony, which were unambiguously aligned for 32 taxa. On the basis of observed (uncorrected) distances, $\mathrm{Hg}$ Pasteuria shared $93.2 \%$ sequence identity with $P$. ramosa, as opposed to the $87 \cdot 3,84 \cdot 7,83 \cdot 3,80 \cdot 4$ and $75.1 \%$ sequence identity found between $\mathrm{Hg}$ Pasteuria and $T$. vulgaris, A. cycloheptanicus, B. subtilis, A. bovis and $E$. coli, respectively. For comparison, sequence similarities between $A$. acidocaldarius and $A$. acidoterrestris and between $T$. vulgaris and $T$. candidus were 99.4 and $98.5 \%$, respectively. The analysis of signal content, after removal of invariant and autapomorphic sites, indicated a significant (tRASA $=12.992, P<$ $0.001)$ cladistic structure in the data. Phylogenetic inference using ML placed $\mathrm{Hg}$ Pasteuria and P. ramosa at the base of a clade that contained Alicyclobacillus spp., B. tusciae and a strain (ALV) of a facultatively thermophilic iron-oxidizer (Fig. 1). Six equally parsimonious trees, 2972 steps long with a rescaled consistency index of $0 \cdot 2$ each, were recovered by MP analysis. Four of the six trees (and, hence, the consensus tree) concurred with the ML tree in placing $\mathrm{Hg}$ Pasteuria and P. ramosa in the same branch as Alicyclobacillus spp., B. tusciae and ALV, there being similar bootstrap values for these relationships (result not shown). The other two most parsimonious trees recovered the Pasteuria (Hg Pasteuria and P. ramosa) as a separate cluster between the branch leading to Alicyclobacillus spp. and B. tusciae and the branch leading to Thermoactinomyces spp. and HTA1417, a strain of an unidentified low-G + C-DNA Grampositive bacterium (result not shown). Similar topology was obtained when the NJ tree was constructed from LogDet-transformed distances based on all sites (result not shown). However, when LogDet-transformed distances were calculated from parsimony sites only, the NJ tree was consistent with both the ML and MP consensus trees regarding the position of Pasteuria spp. (Fig. 2). Unlike the ML tree, the NJ and MP consensus trees placed $B$. schlegelii at the base of the branch leading to the Alicyclobacillus group, although 


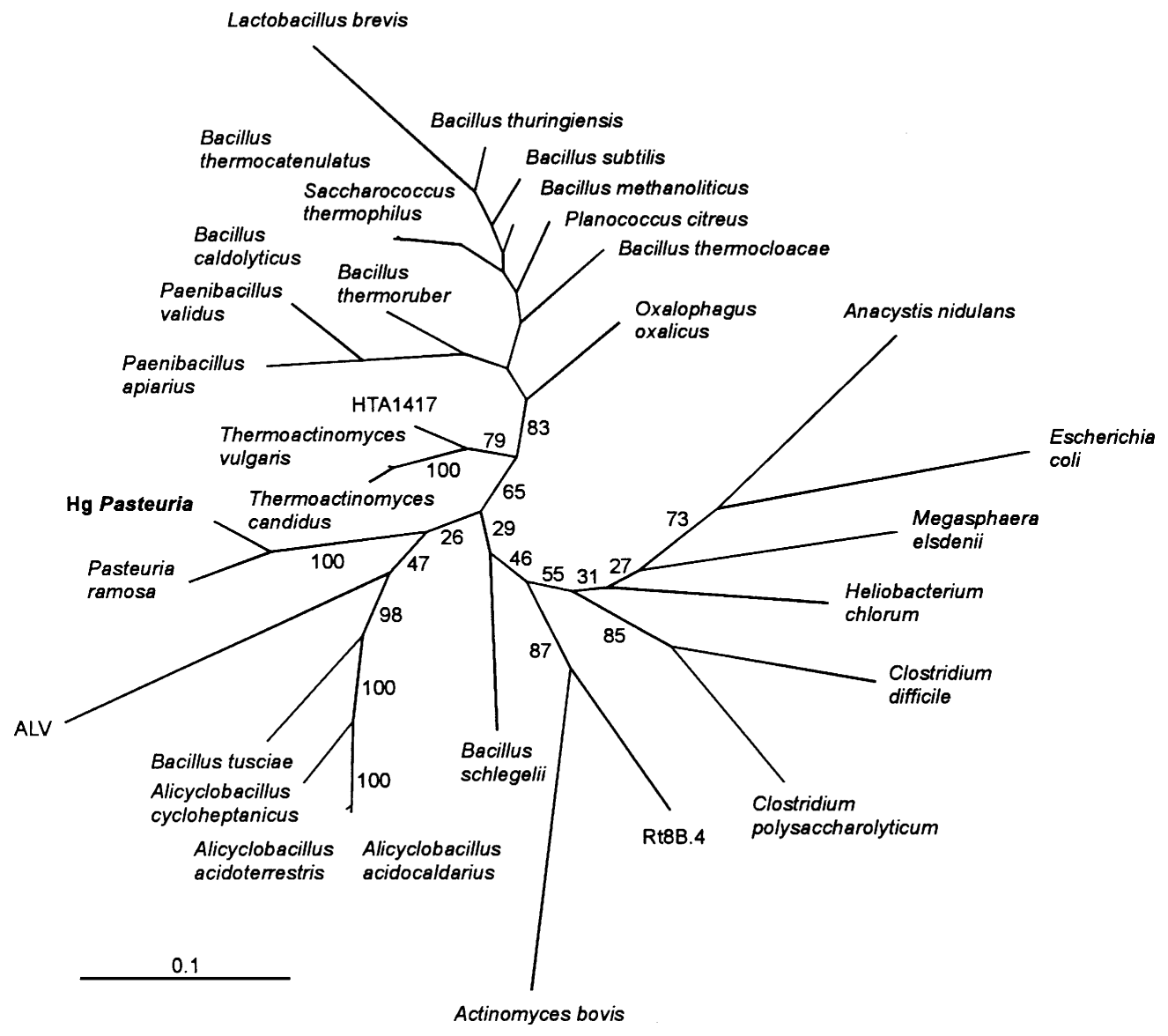

Fig. 1. Phylogenetic reconstruction based on maximum-likelihood analysis of $16 \mathrm{~S}$ rDNA sequences from 32 bacterial species including $\mathrm{Hg}$ Pasteuria (Heterodera glycines-infecting Pasteuria). A. nidulans (cyanobacteria) and E. coli (Proteobacteria) were used as outgroup taxa. Bootstrap proportions (100 replicates) are given for relevant branches only; the scale represents the mean number of nucleotide substitutions per site.

the bootstrap support for this position was poor (18 and $11 \%$, respectively, for the $\mathrm{NJ}$ and the MP consensus trees). Strain ALV was not recovered with Pasteuria spp. in any of the NJ trees.

\section{DISCUSSION}

\section{Provision of clean Pasteuria DNA for PCR amplification}

The absence of vegetative cells in the pre-lysis suspension of endospores, as evidenced by both microscopic and cultural observations, shows that the heat and lysozyme treatments were effective in destroying contaminating bacteria present in the stock suspension. The identity of the DNA amplified from the preand post-lysis suspensions of endospores indicates that, following destruction (by DNase and RNase) of the nucleic acids released (mostly from contaminating bacteria) under the heat and lysozyme treatments, proteinase $\mathrm{K}$ and SDS were able to destabilize Pasteuria endospores sufficiently to enable release of the DNA amplified during the PCR reaction. The assumption that the amplified DNA originated from
Pasteuria rather than from contaminating bacteria is supported by the fact that the resulting sequence was not only very similar to that of $P$. ramosa, the only Pasteuria sequence currently available in the public domain, but also contained the Pasteuria-specific oligonucleotide (Ebert et al., 1996). The identity between the amplicons from the pre- and post-lysis suspensions also suggests that the task of extracting and sequencing DNA from Pasteuria endospores can now be simplified by eliminating unnecessary steps such as glass-bead beating and subsequent DNA purification.

\section{Hg Pasteuria and $P$. ramosa are closely related but distinct species}

According to current criteria for delineating bacterial species (Stackebrandt \& Goebel, 1994; Wayne et al., 1987) $\mathrm{Hg}$ Pasteuria and P. ramosa are closely related but different species. Both Pasteuria belong to a cluster of thermophilic endospore-forming bacilli that differ enough from the other members of the genus Bacillus to warrant their assignment into separate genera within the Bacillaceae (Wisotzkey et al., 1992). The genus 


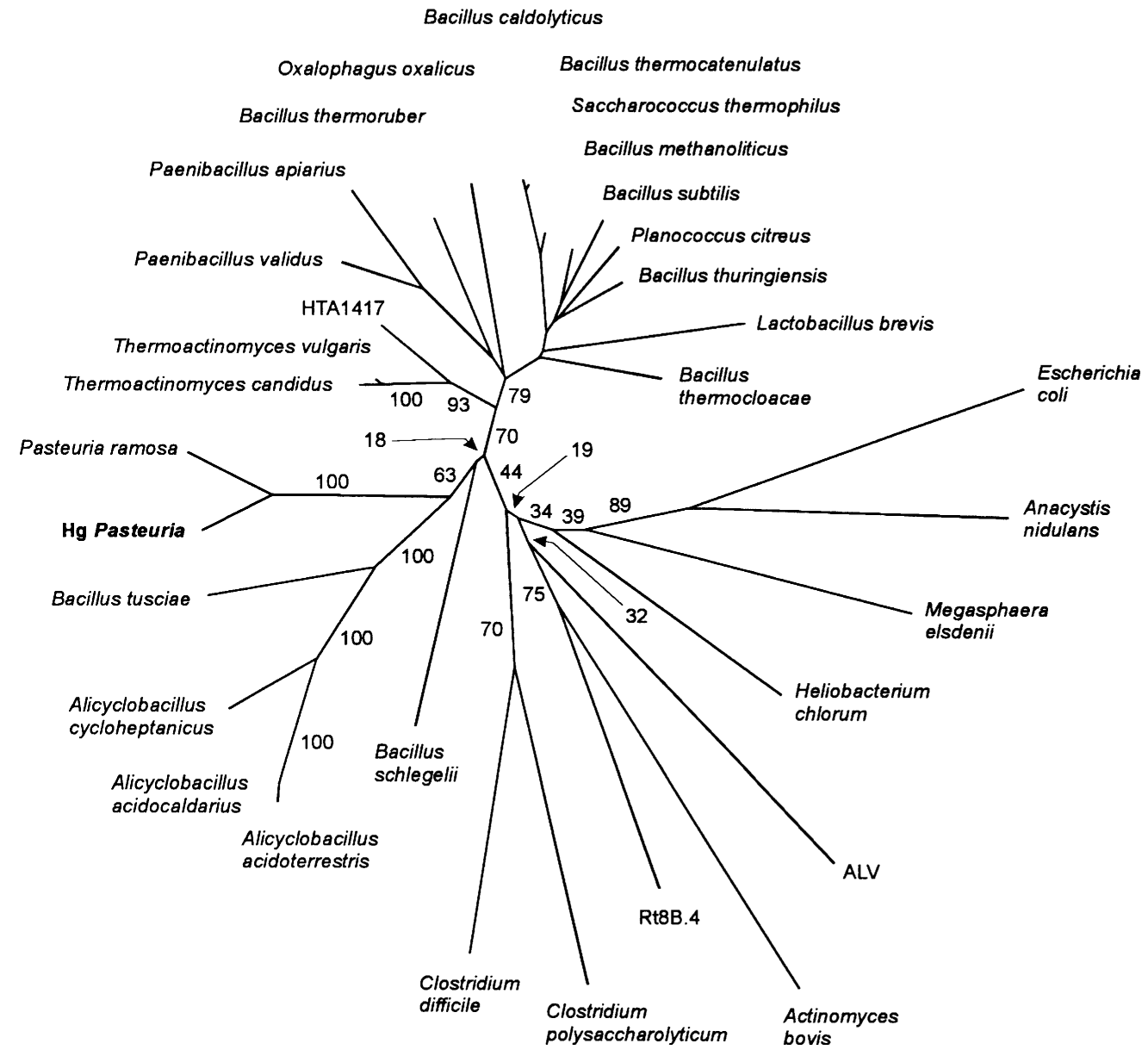

Fig. 2. Neighbour-joining tree derived from the analysis of pair-wise evolutionary distances between the 165 rDNA sequences of 32 bacterial species including $\mathrm{Hg}$ Pasteuria (Heterodera glycines-infecting Pasteuria). A. nidulans (cyanobacteria) and E. coli (Proteobacteria) were used as outgroup taxa. Distances were calculated from parsimony sites only, and the LogDet transformation, which corrects for assymetric base compositions, was applied. In spite of its usefulness in identifying the correct tree, the LogDet transformation generally does not give the amount (or rate) of change along individual branches of the tree, so no scale is provided. Bootstrap proportions (1000 replicates) are indicated for relevant branches only.

Alicyclobacillus, formerly Bacillus, was the first of these 'new genera' to be proposed. It includes thermoacidophilic bacilli that share the rare phenotype of possessing $\omega$-alicyclic fatty acid as the major natural lipid component of the membrane (Wisotzkey et al., 1992). In contrast, the thermophilic chemolithoautotrophs $B$. tusciae and $B$. schlegelii, which group peripherally with Alicyclobacillus spp., do not contain $\omega$-alicyclic fatty acid in their membranes (Rainey et al., 1994; Wisotzkey et al., 1992). It would be interesting to know if Pasteuria spp., which clearly form a distinct line of descent within the 'Alicyclobacillus group', exhibit the $\omega$-alicyclic fatty acid phenotype. The position of strain ALV, an asporogenous and Gramnegative bacterium that clusters with the Grampositive eubacteria (Lane et al., 1992), was not consistent in this study and a previous one (Ebert et al., 1996). Its membership of the 'Alicyclobacillus group' as suggested by the ML and MP methods [which are sensitive to DNA base compositions (Galtier \& Gouy, 1995; Lake, 1994; Lockhart et al., 1994)] did not stand up when evolutionary distances were corrected for bias using the LogDet transformation (Lake, 1994; Lockhart et al., 1994).

\section{Pasteuria spp. and Thermoactinomyces spp. are not as closely related as their morphology would suggest}

At the suprageneric level, Pasteuria spp. were considered morphologically closer to the Actinomycetales, especially T. vulgaris (Sayre \& Starr, 1985; Sayre \& Wergin, 1977), than to the Bacillaceae (Mankau, 1975). As mentioned earlier, Ebert et al. (1996) questioned the position of the genus Pasteuria in the Actinomycetales on the basis of the $16 \mathrm{~S}$ rDNA sequence of $P$. ramosa, but they were unable to provide a definitive answer to the question. To clarify the issue of whether Pasteuria spp. are members of the Actino- 
mycetales, we have considered both the traditional and modern concepts of the actinomycetes. Traditionally, the actinomycetes were defined as bacteria that have the ability to form branching hyphae at some stage of their development (Gottlieb, 1973). This viewpoint was represented in this study by the sequences of $T$. candidus and T. vulgaris. According to modern taxonomists, the Gram-positive division of eubacteria consists of four subdivisions, two of which can be readily distinguished on the basis of DNA composition (Fox et al., 1980; Stackebrandt \& Woese, 1981a; Woese, 1987). The actinomycete subdivision, which was represented by $A$. bovis, includes bacteria with high $\mathrm{G}+\mathrm{C}$ content $(\geqslant 55 \mathrm{~mol} \%)$ and the Clostridium-BacillusStreptococcus subdivision contains bacteria with low $\mathrm{G}+\mathrm{C}$ content $(\leqslant 50 \mathrm{~mol} \%)$. The two minor subdivisions of Gram-positive bacteria, the photosynthetic subdivision and the subdivision of species with Gram-negative walls, were represented by $H$. chlorum and M. elsdenii, respectively.

Several taxa traditionally associated with the actinomycetes have been shown to belong to the low-G + Ccontent subdivision of the Gram-positive bacteria (Fox et al., 1980; Goodfellow \& Cross, 1983; Stackebrandt et al., 1983; Stackebrandt \& Woese, 1981a, b; Woese, 1987). Specifically, T. vulgaris, which has long been regarded as a 'good actinonomycete' (Goodfellow \& Cross, 1983), has been reclassified in the Bacillaceae, thereby indicating that (from a phylogenetic standpoint) possession of hyphae is not as informative as endospore formation (Stackebrandt et al., 1983; Stackebrandt \& Woese, 1981b). Pasteuria spp. and Thermoactinomyces spp. are not closely related either, in spite of their common ability to form branching mycelia. In only three instances in this study (two of six equally parsimonious trees and the NJ tree derived from all sites) were members of the two genera close to each other. As discussed earlier for strain ALV, the $\mathrm{G}+\mathrm{C}$ content could have shifted the position of Pasteuria spp. in the two MP trees, since MP is more sensitive to DNA base composition bias than the ML method (Galtier \& Gouy, 1995; Lake, 1994; Lockhart et al., 1994). Although the LogDet transformation effectively corrects for unequal base compositions, it is still not clear which sites should be used for the correction. There are some indications that inclusion of all sites could result in serious underestimation of the amount of change, particularly for anciently diverged sequences (Lockhart et al., 1994).

The results presented herein are consistent with the view that the genus Pasteuria is a deeply rooted member of the Clostridium-Bacillus-Streptococcus branch of the Gram-positive eubacteria, neither related to the actinomycetes nor closely related to true endospore-forming bacteria (Berkeley \& Ali, 1994). We are currently designing Pasteuria-specific primers that will allow the amplification and sequencing of Pasteuria DNA from limited amounts of endospores. These procedural improvements are likely to stimulate the sequencing of $16 \mathrm{~S}$ rDNA from many isolates of
Pasteuria (including $P$. nishizawae, which was not available during the present study). As more of these sequences become available, it should be possible to validate species and to determine the phylogenetic relationships among the various isolates of Pasteuria.

\section{ACKNOWLEDGEMENTS}

The authors thank Gary J. Olsen, Department of Microbiology, for providing and setting up the fastDNAml program. We are also grateful to Charles A. Smyth and A. Chen, Department of Crop Sciences, for assistance with the personal computer used as server for running bootstrap analyses.

\section{NOTE ADDED IN PROOF}

While this paper was in press, the $16 \mathrm{~S}$ rDNA sequence for Pasteuria penetrans was published by Anderson et al. (1999). Thus, our statement in the Introduction that no nematode-infecting Pasteuria species had been sequenced no longer holds true. $P$. penetrans is a different species to that studied in the present paper.

\section{REFERENCES}

Altschul, S. F., Gish, W., Miller, W., Myers, E. W. \& Lipman, D. J. (1990). Basic local alignment search tool. J Mol Biol 215, 403-410.

Anderson, J. M., Preston, J. F., Dickson, D. W., Hewlett, T. E., Williams, N. H. \& Maruniak, J. E. (1999). Phylogenetic analysis of Pasteuria penetrans by $16 \mathrm{~S}$ rDNA gene cloning and sequencing. J Nematol 31, 319-325.

Atibalentja, N., Noel, G. R., Liao, T. F. \& Gertner, G. Z. (1998). Population changes in Heterodera glycines and its bacterial parasite Pasteuria sp. in naturally infested soil. J Nematol 30, 81-92.

Berkeley, R. C. W. \& Ali, N. (1994). Classification and identification of endospore-forming bacteria. In Fundamental and Applied Aspects of Bacterial Spores, pp. 1-8. Edited by G. W. Gould, A. D. Russell \& D. E. S. Stewart-Tull. Boston, MA: Blackwell.

Bishop, A. H. \& Ellar, D. J. (1991). Attempts to culture Pasteuria penetrans in vitro. Biocontrol Sci Technol 1, 101-114.

Brosius, J., Palmer, M. L., Kennedy, P. J. \& Noller, H. F. (1978). Complete nucleotide sequence of a $16 \mathrm{~S}$ ribosomal RNA gene from Escherichia coli. Proc Natl Acad Sci USA 75, 4801-4805.

Brown, S. M., Kepner, J. L. \& Smart, G. C., Jr (1985). Increased crop yields following applications of Bacillus penetrans to field plots infested with Meloidogyne incognita. Soil Biol Biochem 17, 483-486.

Chen, Z. X. \& Dickson, D. W. (1998). Review of Pasteuria penetrans: biology, ecology, and biological control potential. J Nematol 30, 313-340.

Chen, Z. X., Dickson, D. W., McSorley, R., Mitchell, D. J. \& Hewlett, T. E. (1996). Suppression of Meloidogyne arenaria race 1 by soil application of endospores of Pasteuria penetrans. J Nematol 28, 159-168.

Chen, Z. X., Dickson, D. W., Mitchell, D. J., McSorley, R. \& Hewlett, T. E. (1997). Suppression mechanisms of Meloidogyne arenaria race 1 by Pasteuria penetrans. J Nematol 29, 1-8. 
Ciancio, A. (1995). Phenotypic adaptations in Pasteuria spp. nematode parasites. J Nematol 27, 328-338.

Ciancio, A., Bonsignore, R., Vovlas, N. \& Lamberti, F. (1994). Host records and spore morphometrics of Pasteuria penetrans group parasites of nematodes. J Invertebr Pathol 63, 260-267.

Davies, K. G., Flynn, C. A., Laird, V. \& Kerry, B. R. (1990). The lifecycle, population dynamics and host specificity of a parasite of Heterodera avenae, similar to Pasteuria penetrans. Rev Nematol 13, 303-309.

Duponnois, R. \& Ba, A. M. (1998). Influence of the microbial community of a Sahel soil on the interactions between Meloidogyne javanica and Pasteuria penetrans. Nematologica 44, 331-343.

Ebert, D., Rainey, P., Embley, T. M. \& Scholz, D. (1996). Development, life cycle, ultrastructure and phylogenetic position of Pasteuria ramosa Metchnikoff 1888: rediscovery of an obligate endoparasite of Daphnia magna Straus. Philos Trans $R$ Soc Lond B 351, 1689-1701.

Felsenstein, J. (1981). Evolutionary trees from DNA sequences: a maximum likelihood approach. J Mol Evol 17, 368-376.

Felsenstein, J. (1985). Confidence limits on phylogenies: an approach using the bootstrap. Evolution 39, 783-791.

Felsenstein, J. (1993). PHYLIP (phylogeny inference package), version 3.5c. Seattle: Department of Genetics, University of Washington, USA.

Fox, G. E., Stackebrandt, E., Hespell, R. B. \& 16 other authors (1980). The phylogeny of prokaryotes. Science 209, 457-463.

Galtier, N. \& Gouy, M. (1995). Inferring phylogenies from DNA sequences of unequal base compositions. Proc Natl Acad Sci USA 92, 11317-11321.

Galtier, N., Gouy, M. \& Gautier, C. (1996). SEAVIEW and PHYLO_ WIN: two graphic tools for sequence alignment and molecular phylogeny. CABIOS 12, 543-548.

Giblin-Davis, R. M. (1990). Potential for biological control of phytoparasitc nematodes in bermudagrass turf with isolates of the Pasteuria penetrans group. Proc Fla State Hort Soc 103, 349-351.

Giblin-Davis, R. M., McDaniel, L. L. \& Bilz, F. G. (1990). Isolates of the Pasteuria penetrans group from phytoparasitic nematodes in bermudagrass turf. Suppl J Nematol 22, 750-762.

Goodfellow, M. \& Cross, T. (1983). Classification. In The Biology of the Actinomycetes, pp. 7-164. Edited by M. Goodfellow, M. Mordarski \& S. T. Williams. London: Academic Press.

Gottlieb, D. (1973). General consideration and implications of the Actinomycetales. In Actinomycetales: Characteristics and Practical Importance, pp. 1-10. Edited by G. Sykes \& F. A. Skinner. London: Academic Press.

Gowen, S. R., Tzortzakakis, E. A. \& Channer, A. G. De R. (1998). Control of the root-knot nematode Meloidogyne javanica by the parasite Pasteuria penetrans as influenced by the initial nematode population densities. Nematologica 44, 369-379.

Lake, J. A. (1994). Reconstructing evolutionary trees from DNA and protein sequences: paralinear distances. Proc Natl Acad Sci USA 91, 1455-1459.

Lane, D. J., Harrisson, A. P., Jr, Stahl, D., Pace, B., Giovannoni, S. J., Olsen, G. J. \& Pace, N. R. (1992). Evolutionary relationships among sulfur- and iron-oxidizing eubacteria. J Bacteriol 174, 269-278.

Lockhart, P. J., Steel, M. A., Hendy, M. D. \& Penny, D. (1994). Recovering evolutionary trees under a more realistic model of sequence evolution. Mol Biol Evol 11, 605-612.
Lyons-Weiler, J., Hoelzer, G. A. \& Tausch, R. J. (1996). Relative Apparent Synapomorphy Analysis (RASA) I: the statistical measurement of phylogenetic signal. Mol Biol Evol 13, 749-757.

Maidak, B., Cole, J. R., Parker, C. T., Jr \& 11 other authors (1999). A new version of the RDP (Ribosomal Database Project). Nucleic Acids Res 27, 171-173.

Mankau, R. (1975). Bacillus penetrans n. comb. causing a virulent disease of plant-parasitic nematodes. J Invertebr Pathol 26, 333-339.

Metchnikoff, M. E. (1888). Pasteuria ramosa. Un représentant des bactéries à division longitudinale. Ann Inst Pasteur 2, 165-170.

Nishizawa, T. (1987). A decline phenomenon in a population of the upland rice cyst nematode, Heterodera elachista, caused by a bacterial parasite, Pasteuria penetrans. J Nematol 19, 546 (Abstr.).

Noel, G. R. \& Stanger, B. A. (1994). First report of Pasteuria sp. attacking Heterodera glycines in North America. Suppl $J$ Nematol 26, 612-615.

Olsen, G. J., Matsuda, H., Hagstrom, R. \& Overbeek, R. (1994). fastDNAml: a tool for construction of phylogenetic trees of DNA sequences using maximum likelihood. CABIOS 10, 41-48.

Rainey, F. A., Fritze, D. \& Stackebrandt, E. (1994). The phylogenetic diversity of thermophilic members of the genus Bacillus as revealed by $16 \mathrm{~S}$ rDNA analysis. FEMS Microbiol Lett $\mathbf{1 1 5}$, 205-212.

Relman, D. A., Loutit, J. S., Schmidt, T. M., Falkow, S. \& Tompkins, L. S. (1990). The agent of bacillary angiomatosis. An approach to the identification of uncultured pathogens. New Engl J Med 323, 1573-1580.

Relman, D. A., Schmidt, T. M., MacDermott, R. P. \& Falkow, S. (1992). Identification of the uncultured bacillus of Whipple's disease. New Engl J Med 327, 293-301.

Saitou, N. \& Nei, M. (1987). The neighbor-joining method: a new method for reconstructing phylogenetic trees. Mol Biol Evol 8, 49-70.

Sambrook, J., Fritsch, E. F. \& Maniatis, T. (1989). Molecular Cloning : a Laboratory Manual, 2nd edn. Cold Spring Harbor, NY: Cold Spring Harbor Laboratory.

Sayre, R. M. \& Starr, M. P. (1985). Pasteuria penetrans (ex Thorne, 1940) nom. rev., comb. n., sp. n., a mycelial and endosporeforming bacterium parasitic in plant-parasitic nematodes. Proc Helminthol Soc Wash 52, 149-165.

Sayre, R. M. \& Starr, M. P. (1988). Bacterial diseases and antagonisms of nematodes. In Diseases of Nematodes, pp. 69-101. Edited by G. O. Poinar, Jr \& H.-B. Janson. Boca Raton, FL: CRC Press.

Sayre, R. M. \& Starr, M. P. (1989). Genus Pasteuria Metchnikoff 1888, 166 ${ }^{\mathrm{AL}}$ emend. Sayre and Starr 1985, 149, Starr and Sayre 1988a, 27 (Nom. Cons. Opin. 61 Jud. Comm. 1986, 119. Not Pasteuria in the sense of Henrici and Johnson (1935), Hirsch (1972), or Staley (1973); see Starr et al. (1983) and Judicial Commission (1986). In Bergey's Manual of Systematic Bacteriology, vol. 4, pp. 2601-2615. Edited by S. T. Williams, M. E. Sharpe \& J. G. Holt. Baltimore: Williams \& Wilkins.

Sayre, R. M. \& Wergin, W. P. (1977). Bacterial parasite of a plant nematode: morphology and ultrastructure. J Bacteriol 129, 1091-1101.

Sayre, R. M., Adams, J. R. \& Wergin, W. P. (1979). Bacterial parasite of a cladoceran: morphology, development in vivo, 
and taxonomic relationships with Pasteuria ramosa. Int J Syst Bacteriol 29, 252-262.

Sayre, R. M., Gherna, R. L. \& Wergin, W. P. (1983). Morphological and taxonomic re-evaluation of Pasteuria ramosa Metchnikoff 1888 and 'Bacillus penetrans' Mankau 1975. Int J Syst Bacteriol 33, 636-649.

Sayre, R. M., Wergin, W. P., Nishizawa, T. \& Starr, M. P. (1991a). Light and electron microscopical study of a bacterial parasite from the cyst nematode, Heterodera glycines. J Helminthol Soc Wash 58, 69-81.

Sayre, R. M., Wergin, W. P., Schmidt, J. M. \& Starr, M. P. (1991b). Pasteuria nishizawae sp. nov., a mycelial and endosporeforming bacterium parasitic on cyst nematodes of genera Heterodera and Globodera. Res Microbiol 142, 551-564.

Stackebrandt, E. \& Goebel, B. M. (1994). Taxonomic note: a place for DNA-DNA reassociation and 16S rRNA sequence analysis in the present species definition in bacteriology. Int $J$ Syst Bacteriol 44, 846-849.

Stackebrandt, E. \& Woese, C. R. (1981a). The evolution of prokaryotes. In Molecular and Cellular Aspects of Microbial Evolution, pp. 1-31. Edited by M. J. Carlite, J. F. Collins \& B. E. B. Moseley. Cambridge: Cambridge University Press.

Stackebrandt, E. \& Woese, C. R. (1981b). Towards a phylogeny of the actinomycetes and related organisms. Curr Microbiol 5, 197-202.

Stackebrandt, E., Ludwig, W., Seewaldt, E. \& Schleifer, K.-H. (1983). Phylogeny of sporeforming members of the order Actinomycetales. Int J Syst Bacteriol 33, 173-180.

Starr, M. P. \& Sayre, R. M. (1988). Pasteuria thornei sp. nov. and Pasteuria penetrans sensu stricto emend., mycelial and endospore-forming bacteria parasitic, respectively, on plantparasitic nematodes of the genera Pratylenchus and Meloidogyne. Ann Inst Pasteur Microbiol 139, 11-31.
Sturhan, D. (1988). New host and geographical records of nematode-parasitic bacteria of the Pasteuria penetrans group. Nematologica 34, 350-356.

Sturhan, D., Winkelheide, R., Sayre, R. M. \& Wergin, W. P. (1994). Light and electron microscopical studies of the life cycle and developmental stages of a Pasteuria isolate parasitizing the pea cyst nematode, Heterodera goettingiana. Fundam Appl Nematol 17, 29-42.

Swofford, D. L. (1993). PAUP: phylogenetic analysis using parsimony, version 3.1. Champaign, IL: Illinois Natural History Survey.

Thompson, J. D., Gibson, T. J., Plewniak, F., Jeanmougin, F. \& Higgins, D. G. (1997). The CLUSTALX windows interface: flexible strategies for multiple sequence alignment aided by quality analysis tools. Nucleic Acids Res 25, 4876-4882.

Wayne, L. G., Brenner, D. J., Colwell, R. R. \& 9 other authors (1987). International Committee on Systematic Bacteriology. Report of the ad hoc committee on reconciliation of approaches to bacterial systematics. Int J Syst Bacteriol 37, 463-464.

Weibelzahl-Fulton, E., Dickson, D. W. \& Whitty, E. B. (1996). Suppression of Meloidogyne incognita and $M$. javanica by Pasteuria penetrans in field soil. $J$ Nematol 28, 43-49.

Williams, A. B., Stirling, G. R., Hayward, A. C. \& Perry, J. (1989). Properties and attempted culture of Pasteuria penetrans, a bacterial parasite of root-knot nematodes (Meloidogyne javanica). J Appl Bacteriol 67, 145-156.

Wisotzkey, J. D., Jurtshuk, P., Jr, Fox, G. E., Deinhard, G. \& Poralla, K. (1992). Comparative sequence analyses on the $16 \mathrm{~S}$ rRNA (rDNA) of Bacillus acidocaldarius, Bacillus acidoterrestris, and Bacillus cycloheptanicus and proposal for creation of a new genus, Alicyclobacillus gen. nov. Int J Syst Bacteriol 42, 263-269.

Woese, C. R. (1987). Bacterial evolution. Microbiol Rev 51, 221-271. 